\title{
Energy intensity of the economy as a variable to measure the energy efficiency of a country: comparison between European member states
}

\author{
A. Martínez, S. Valero, E. Velasco and C. Senabre \\ Electrical Engineering Area \\ Universidad Miguel Hernández de Elche \\ Avd. de la Universidad s/n. Edificio Quorum-V, 03203 Elche (Spain) \\ Phone: 0034966658969 / 616201717, e-mail: alberto.martinez@umh.es, svalero@umh.es
}

\begin{abstract}
When renewable energies were included in the energy policies of the EU partners, a target was set for $2020 ; 20 \%$ of the energy production in the member states should be renewable. However, with the beginning of the economic crisis in 2007, growth forecasts were not met; there was an overcapacity in certain countries, which meant that the energy situation had to be reconsidered to develop a stronger, more consolidated interconnection among member states and therefore ensure a secure quality supply, in which the technical and financial management of the system is balanced and there is less dependence on foreign energy. Supporting a mix of energy sources based on a high penetration of renewables is putting pressure on the electricity tariffs. Hence, renewables should be promoted but without negatively affecting the competitiveness of countries.
\end{abstract}

In a recession, efficiency indicators, not growth at any price must be controlled. Therefore, a key indicator to be considered is the Energy Intensity of the Economy that compares the total primary energy consumption and the GDP.

Any discussion of energy strategy should focus on three fundamental parameters: security of supply, environmental sustainability and economic efficiency. The energy policies of EU countries are based on these three key areas.

\section{Key words}

Energy, generation, electricity, efficiency, renewable.

\section{Introduction}

The growth of the EU member state economies has suffered in recent years. Furthermore, considering the energy situation of different countries with their high dependence on oil and their energy balance structure, their dependence on foreign energy and the energy deficit persists (see Figure 1).

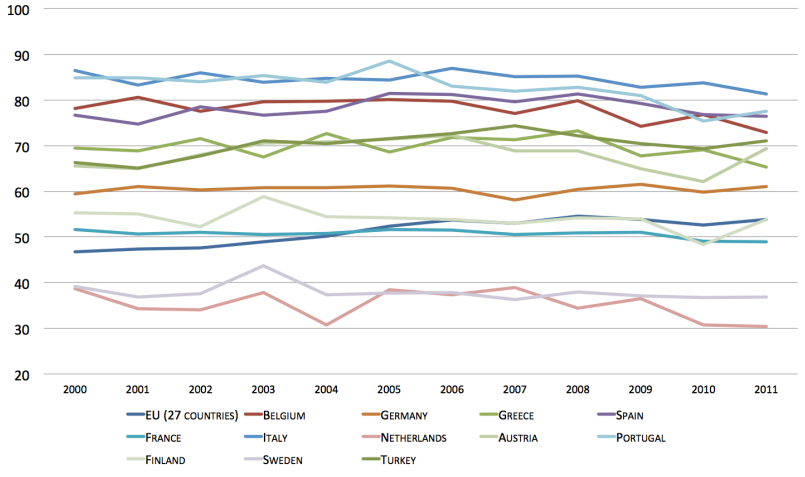

Fig. 1. Energy dependence (\%) Source: Eurostat [1]

The infrastructure of electricity is oversized in some countries because of the predicted fatal errors and the economic crisis. This has given rise to an immense power generation infrastructure that has resulted in an overcapacity to satisfy the demand for electricity; this then exacerbates the tension and volatility of energy and electricity prices in particular.

The strategic objectives of the European Commission in January 2007 for an "Energy Policy for Europe" [2]-[3] focused on three areas: ensuring the competitiveness of the European economies, promoting environmental sustainability and increasing the security of energy supply by establishing a common foreign policy dialogue among Member States. This policy was supported by the European Council in March of that year, when it adopted an integrated policy on climate and energy, pledging to achieve the following goals by 2020 : a $20 \%$ reduction in GHG emissions, compared to the 1990 levels, a 20\% rise in the share of renewables in energy consumption and a $20 \%$ improvement in energy efficiency. This indicator was reduced to $10 \%$ following the Agreement [4] that was reached between the European Parliament, the Council and the negotiating committees on June $14^{\text {th }}$, 2012, which was justified by the effects of the crisis on investment in new infrastructure and technologies and the slow progress made by member states in energy efficiency, as their governments were still not completely convinced about energy efficiency being the way to get 
out of the economic, environmental and social crisis (see Figure 2).

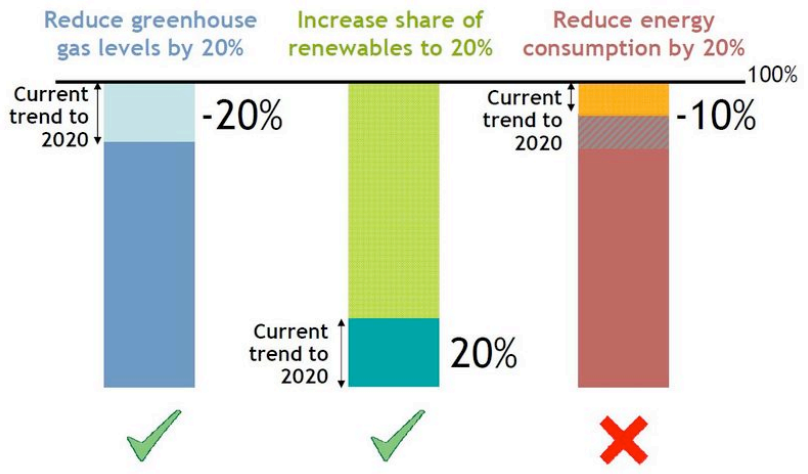

Fig. 2. EU greenhouse gas emissions reduction status June 2012 Source: Zeiss, G. "New EU energy efficiency directive to address 20-20-20 shortfall" [online]

The attempts of the member countries to adapt policies produced by the EU are important and the decisions of the different governments of the member states will be crucial in the years to come. However, countries' diverse energy situations make it more difficult to attain the objectives established. This complexity can only be tackled through by means of the technological transformation of the energy system [5], to make electrical networks flexible through the firm commitment of governments to legislate and promote distributed generation, balance technical and economical electrical systems, and encourage investment in intelligent grids and storage distribution, which will ultimately increase the energy efficiency of a country.

\section{Problems and the analysis of the main challenges}

With regard to renewables, there are questions and doubts about the timing of these technologies being launched and integrating them in with other energy generation sources to form a sustainable mix of electricity production (see Figure 3). Great dependency on renewable energy is very expensive for the Technical Operator of a system, because in the absence of generation sources, the power supply still has to be ensured. Therefore, the benchmark $20 \%$ goal of the final energy consumption being satisfied by renewable sources [6] is adequate, as long as the two aspects are balanced: firstly, the supply with certain characteristics of the generation mix has to be ensured, which allows in then provides for the moderate evolution of energy prices, and less dependence on foreign energy.

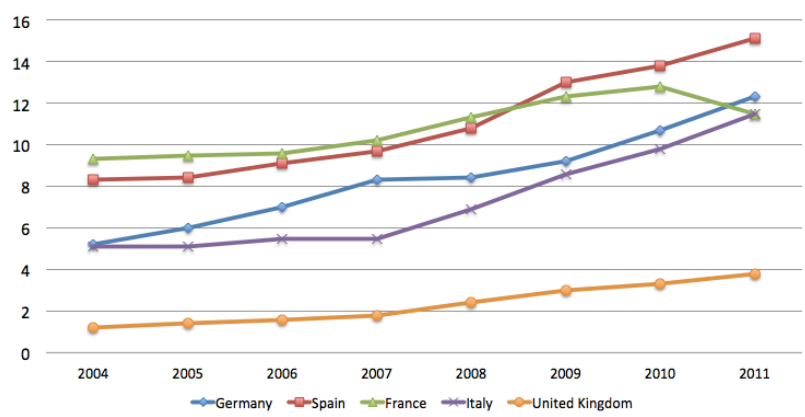

Fig. 3. Share of renewable energy in gross final energy consumption (\%) Source: Eurostat [1]
Therefore, this article focuses on the variables that come into play when defining the energy efficiency of the economy of a country: the influence that the generation mix has on the energy efficiency of the economy, the ratio of the country's energy dependence and its relationship with the GDP, as well as the sensitivity of electricity prices depending on the generation mix in different European countries which shows that an energy system that is overly dependent on renewables could become unsustainable in the medium term.

\section{Tools as possible indicators}

Nevertheless, how can the indicators be defined to get an idea of how a country's energy technology is evolving and what its relationship with the generation of value is? In other words, is there an indicator that can be used to assess a country's degree of competitiveness and energy efficiency? In an environment of a recession, efficiency indicators, not growth at any price, have to be controlled. Therefore, a key indicator to be considered is the Energy Intensity of the Economy that compares the total primary energy consumption and the GDP. This ratio measures the energy consumed by an economy and its energy efficiency coverage. Ultimately, this ratio points to the efficiency of the economy. There is a comparison of the EIE of several European countries in Figure 4.

This ratio is then analyzed. The GDP at real prices has to be used, the total final demand for goods and services over a year is considered and the GDP in real terms (constant prices) is required, because otherwise (nominal) a comparison cannot be made between the energy technologies that have been used in this period and the corresponding updated levels of inflation or deflation.

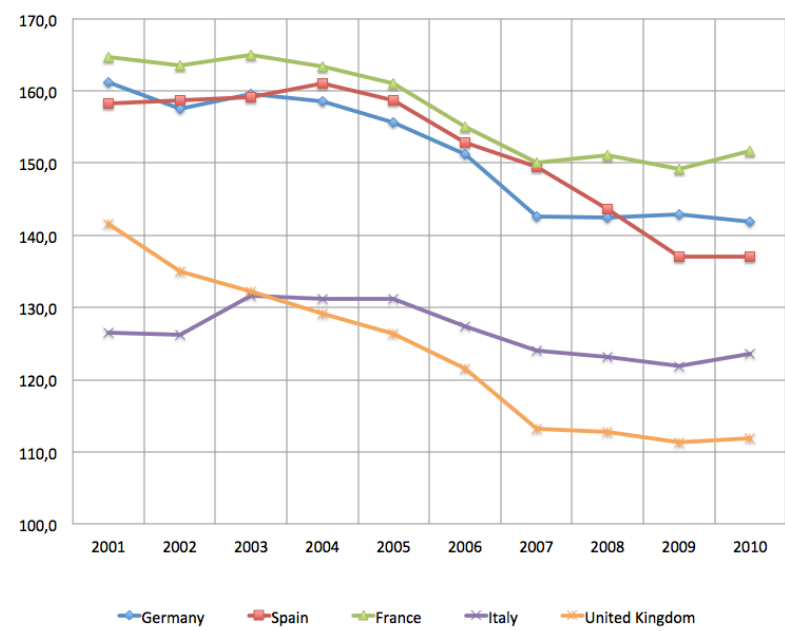

Fig. 4. Energy Intensity of Economy (kgoe/1000€ of Real GDP 2005 base year) Source: Eurostat [1]

A group of countries within the European Union were selected and grouped together according to their demographics. A number of interesting conclusions were obtained from a comparison of the values of Energy Intensity of the Economy in Figure 4: the country with the highest efficiency in its most efficient economy is United Kingdom, closely followed by Italy, and finally, 
at the end of the list and in the following order: Spain, Germany and France.

About the analysis of the distribution of the GDP per sectors and their influence on the Energy Intensity of the Economy indicator, emphasize the difference between the average EIE index of the industrial and services sector, where the former is much more intensive in energy consumption (about 15-1). The GDP distribution structures are similar in this case of study, as shown in Figure 5, but falls down of the industrial sector normally results a significant reduction of the EIE, for example in the case of Spain since 2000 [7].

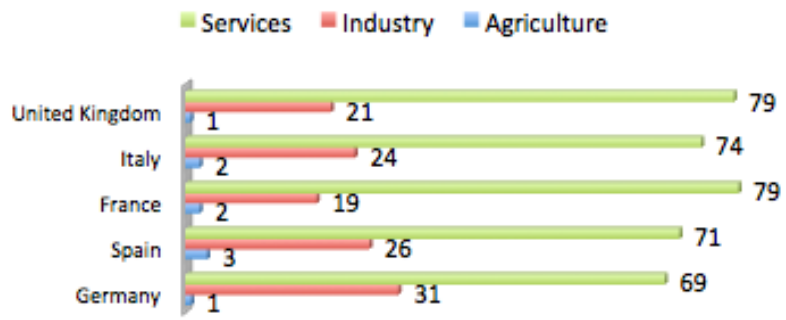

Fig. 5. GDP by Sector in 2012 (\%) Source: CIA [8] and IMF [9]

The analysis of the degree of dependence on foreign energy is not conclusive, as shown in Figure 6, where Italy was found to be the country that is the most dependent, closely followed by Spain. It is worth noting that the United Kingdom, which had negative rates earlier on in the decade (a high rate of self-sufficiency), has evolved positively, although this evolution is always lower and unlike that of the other countries analyzed. However, the aforesaid trend shown by the UK does not apply to the evolution of its Energy Efficiency indicator of the Economy, so the positive trend of the Energy Intensity of the Economy using this parameter cannot be completely justified.

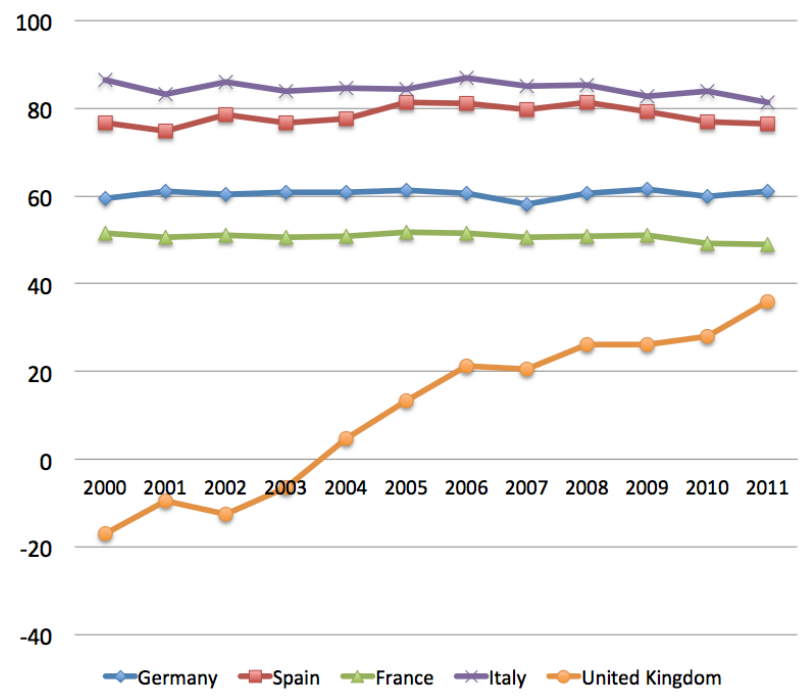

Fig. 6. Energy dependence (\%) Source: Eurostat [1]

The higher level of Energy Efficiency of the Economy of certain countries can be explained by the relevance of renewable energy in energy consumption. But as shown in Figure 3, this assumption is wrong. Nothing could be further from the truth: In Italy and the UK, the two top countries with the best Energy Efficiency of the Economy, renewables have less of a bearing on the final energy consumption.

Finally, the variables related to energy transformations have to be analyzed: primary energy production, total consumption of primary energy and final energy consumption.

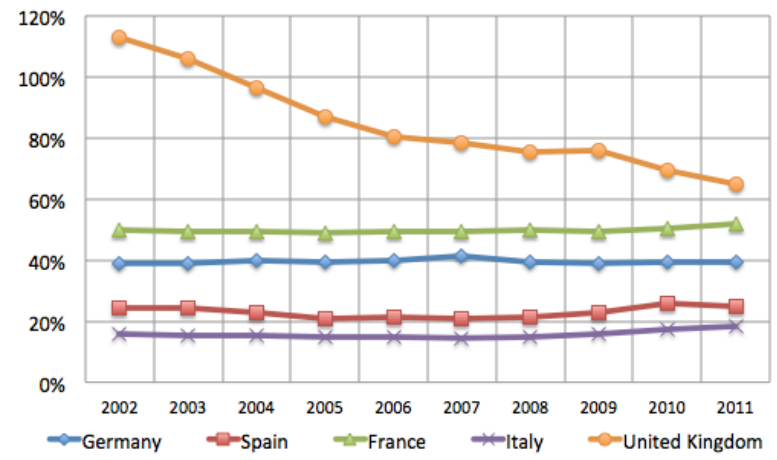

Fig. 7. Primary production/Gross inland consumption (\%) Source: Eurostat [1]

The first ratio is defined as Primary production / Gross inland consumption. This indicator measures the efficiency: the primary energy that the country is capable of producing with regard to the total primary energy consumption, as shown in Figure 7. The United Kingdom has a negative trend compared to other European countries that remains constant; its external energy dependence is growing, quite distant from others, whose growth rates of the Energy Intensity of the Economy are equal since 2007. The case of Italy cannot be established yet; therefore, other parameters that help justify the rate of Energy Intensity of the Economy in these two countries should be used.

Figure 8 shows the Final energy consumption / Gross inland consumption indicator. This is the answer: Italy has a good ratio, which demonstrates the efficiency of energy transformations in the country: the performance of their supply chains of energy, the efficiency of their distribution networks and electricity transmission, its transport and mobility model. This all helps explain Italy's favorable EIE index.

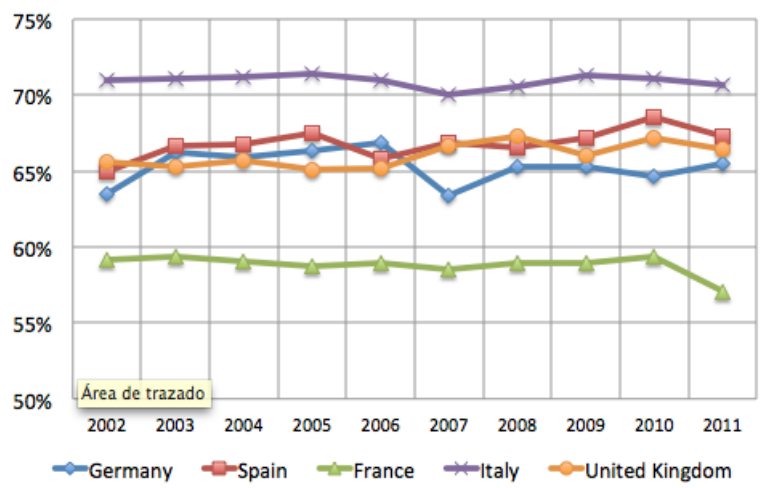

Fig. 8. Final Energy Consumption/Gross inland consumption (\%) Source: Eurostat [1] 
About Electricity sector, is interesting the Electrical Energy Available for Final Consumption / Final Energy Consumption indicator, shows the weight of the electricity in the final energy consumption of the countries. This indicator is related with EIE as shows Figure 9 and interesting data are obtained: in the case of Germany highlights the situation in the quadrant of low efficiency of the economy with low energy dependence of electricity. This contrasts with the situation in countries with low energy intensity of economy (high efficency) located in the quadrant of low electrical dependence and the situation of countries with high EIE (low efficency), located on the diagonal with a large electrical dependence of its economy.

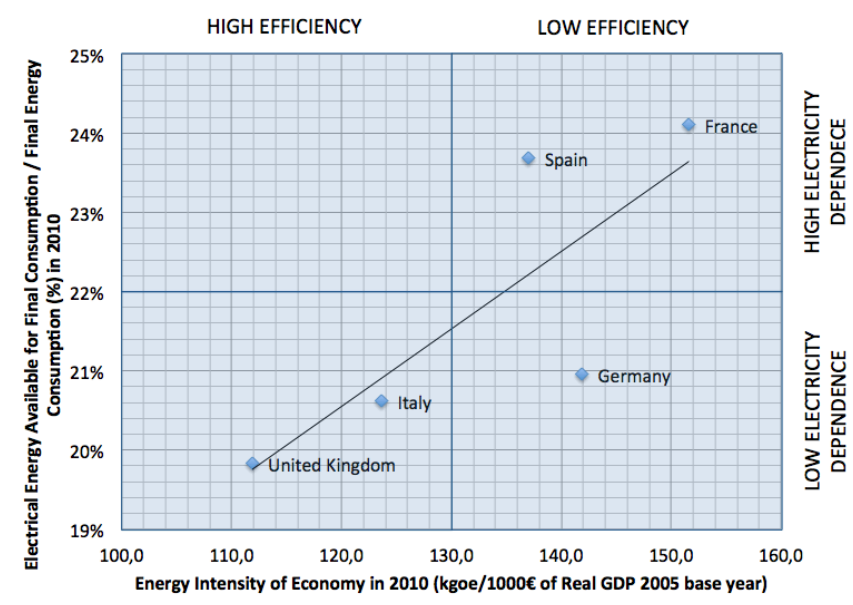

Fig. 9. Energy Intensity of Economy related with Electricity Dependence Indicator. Source: Eurostat [1]

All in all, the evolution of the domestic consumer energy prices is analyzed. Valuable conclusions have been drawn on some of the countries. The reference price refers to energy prices including taxes and levies, except VAT. The generation and supply costs plus that of transport and distribution networks and the taxes needed to support the system are all included.

In Figure 10, France and the UK are seen to have lower electricity prices. Italy and Germany have the highest tariffs. Spain is in the middle of the range but it has a strong growth, just like Germany. Traditionally, electricity prices in Germany are higher than those of some of the neighbouring countries, and are generally above the European average. There are structural reasons for this, particularly Germany's high level of supply security and stringent environmental and climate standards [10].

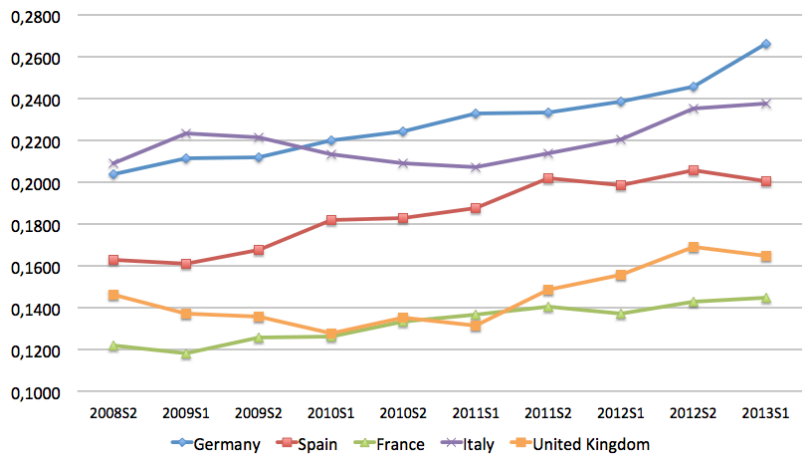

Fig. 10. Price of electricity - Domestic Cons. (including Network Costs and Taxes exc. VAT) $(€ / \mathrm{kWh})$ Source: Eurostat [1]

In the case of France, although the weight of renewables is important in this country compared to the others, nuclear generation is seen to be even more so (see Figure 11 ), as it reaches almost $50 \%$ of its generation capacity and almost $80 \%$ of its gross electricity generation. It is observed that in the last period in France renewables have less bearing on the balance of power installed (see Figure 3). It is the country with the lowest energy prices. With regard to Italy, as previously shown, its use of renewables is average and its nuclear generation is reduced. All this is exacerbated because of its excessive dependence on foreign energy, which results in higher prices. The UK is the most self-sufficient, its use of nuclear energy is moderate and it has the lowest level of renewable power on its balance sheet. It is one of the countries with the lowest prices. Germany has strict policies to reduce nuclear power like Italy, and weighing renewables increasing. It promotes the use of renewables and it has the highest electricity prices. Finally Spain still has average prices, with a low-moderate use of nuclear energy and it invests heavily in developing renewable energy generation.

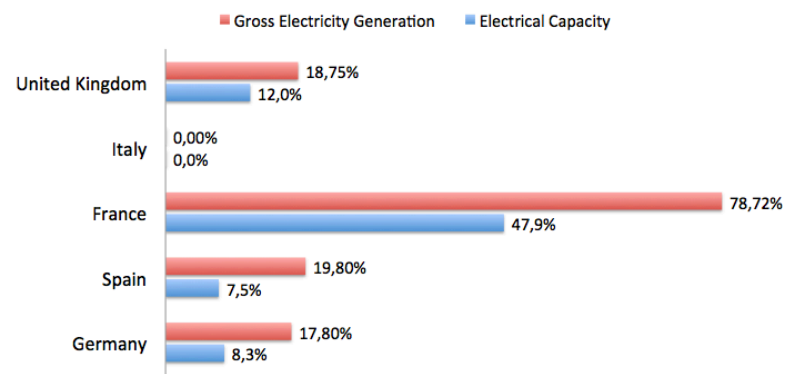

Fig. 11. Share of nuclear power in 2011. Source: Eurostat [1], REE [11] and ENTSO-E [12]

\section{Conclusion}

The Energy Intensity of the Economy is the variable that shows the energy efficiency of a country. In general, a high EIE points to an inefficient economy: high energy consumption to produce a low GDP. In contrast, a reduced EIE indicates an efficient economy with reduced energy consumption. 
There are two indicators that are directly associated with the Gross Inland Consumption variable that explains the favorable Energy Intensity of the Economy in two specific countries perfectly: United Kingdom and Italy. The Primary Production / Gross Inland Consumption ratio that introduce the self-sufficiency aspect related to the primary energy needs, and, in the case of Italy, the Final energy consumption / Gross Inland consumption ratio, which it shows the efficiency of energy transformations in the country: the performance of their supply chains of energy efficiency in their distribution networks and electricity transmission, regulators and finally, the model of transport and mobility.

The higher level of Energy Efficiency of the Economy of countries can't be explained by the relevance of renewable energy in energy consumption, as shown in Figure 3. Indeed, even if renewables potential seems to be sufficient to cover several times energy primary demand, should not be used for load base generation, as their production can be erratic, and hence have always to run in parallel with traditional sources [13]. Maybe the financial schemes used to support the implementation of those technologies are a part of the origin of such inefficiency, but wrong policies about renewables promotion are the other side. The distributed production about renewables is more appropriate. It is therefore important to reach equilibrium via the diversification of the electricity mix and better international connections. A generation mix dominated by intermittent capacities can have unintended consequences, including rising average market price level and worsening price volatility [14].

This complexity can only be tackled through by means of the technological transformation of the energy system [5], to make electrical networks flexible through the firm commitment of governments to legislate and promote distributed generation, balance technical and economical electrical systems, and encourage investment in intelligent grids and storage distribution, which will ultimately increase the energy efficiency of a country.

The conclusions made with regard to a projection analysis of retail domestic consumer prices of electricity are valuable. Factors such as the degree of self-sufficiency, distribution of the GDP per sectors, the share of nuclear power and the development of renewable energy, has a significant influence on are significant when studying the behaviour of the final prices in European countries.

Lastly, it is worth pointing out that those countries where renewables are the most relevant in the final energy consumption have the worst energy efficiency index in the economy. This implies that investment in renewables does not initially favor the energy efficiency in the country's economy. Indeed, a high renewable capacity in the system produces a high percentage of non-manageable and volatile energy [15] that results in a complex mix management, which requires flexibility in the generation to meet high levels of demand for electricity with coal and gas. This is not the optimum way of using the system as it increases fuel costs (lower efficiency) and operating costs (higher demand), it favors the deterioration of the equipment used, which reduces the reliability of such and it raises the amount of money that has to be spent on maintenance and repair work. This could get worse with the increased use of renewable sources and the gradual disappearance of excess capacity.

\section{References}

[1] EUROSTAT [on-line] - European Commission Statistics Database - [consulted 2013]. Available at: http://epp.eurostat.ec.europa.eu/portal/page/portal/eurostat/hom $\mathrm{e} /$

[2] Balázs, Mellár, "Fichas técnicas sobre la Unión Europea UE-FTU 5.7.1. Política Energética en la UE: principios generales, Parlamento Europeo", 2013.

[3] Plan de Energías Renovables [PER] 2011-2020, Instituto para la Diversificación y el Ahorro Energético (IDAE), Madrid, 2011.

[4] Energy efficiency deal halves $20 \%$ target gap, online Press release, The Coalition for Energy Savings, June 2012, [Consulted 26/06/2013].

[5] Energy Technology Perspectives 2012: Pathway to a Clean Energy System, online Paris: OECD/International Energy Agency, ISBN 978-92-64-17488-7.

[6] Análisis de la evolución de la intensidad energética en España, Economics for Energy, 2010, ISSN 2172-8127.

[7] Planificación Energética Indicativa 2011-2020. Secretaría de Estado de Energía. Ministerio de Industria, Energía y Turismo. Madrid - Noviembre 2011. Available at: http://www.minetur.gob.es

[8] CIA [on-line] Central Ingelligence Agency - The World Factbook [Consulted 2013]. Available at: https://www.cia.gov/library/publications/the-world-

factbook/fields/2012.html

[9] IMF [on-line] International Monetary Fund - World Economic Outlook Databases (WEO) [Consulted 2013]. Available at: http://www.imf.org/external/data.htm

[10] Federal Ministry of Economics and Technology (BMWi) and Federal Ministry for the Environtment, Nature Conservation and Nuclear Safety (BMU) - First Monitoring Report "Energy of the future" - December 2012. Available at: http://www.bundesnetzagentur.de/monitoringenergyofthefuture [11] REE [on-line] Red Eléctrica de España - Informe del Sistema Eléctrico Español 2012 - International Comparison [Consulted 2013]. Available at: http://www.ree.es/es/publicaciones/indicadores-y-datosestadisticos

[12] ENTSO-E [on-line] European Network of Transmission System Operators for Electricity [Consulted 2013]. Available on: https://www.entsoe.eu/data/data-portal/

[13] F. Foidart, J. Oliver-Solá, C.M. Gasol, X. Gabarrell, J. Rieradevall, "How important are current energy mix choices on future sustainability? Case study: Belgium and Spain Projections towards 2020-2030" Energy Policy, Volume 38, September 2010, Pages 5028-5037

[14] Irena Milstein, Asher Tishler, "Intermittently renewable energy, optimal capacity mix and prices in a deregulated electricity market" Energy Policy, Volume 39, July 2011, Pages 3922-3927

[15] El modelo eléctrico español en 2030. Escenarios y alternativas. PricewaterhouseCoopers, 2010. 